\title{
Additional Surgery for New Tumor Event Unknown
}

National Cancer Institute

\section{Source}

National Cancer Institute. Additional Surgery for New Tumor Event Unknown. NCI

Thesaurus. Code C160302.

Additional surgery for the new tumor event is unknown. 